\title{
PRODUÇÃO DE BIOMASSA, TEOR E EXPORTAÇÃO DE MACRONUTRIENTES EM PLANTAS DE REPOLHO EM FUNÇÃO DE DOSES DE NITROGÊNIO E DE ESPAÇAMENTOS
}

\author{
Biomass yield, macronutrient uptake and tissue concentration of cabbage as a function \\ of nitrogen rates and plant spacings
}

\author{
Leonardo Angelo de Aquino ${ }^{1}$, Mário Puiatti², Marcelo Magri Lélis ${ }^{3}$, \\ Paulo Roberto Gomes Pereira ${ }^{4}$, Francisco Hevilásio Freire Pereira ${ }^{5}$
}

\begin{abstract}
RESUMO
Avaliou-se o efeito de três espaçamentos $(80 \times 30,60 \times 30$ e $40 \times 30 \mathrm{~cm})$ e de cinco doses de $\mathrm{N}\left(0,75,150,225\right.$ e $\left.300 \mathrm{~kg} \mathrm{ha}^{-1}\right)$ sobre a produção de massa seca (MS), teores e exportação de macronutrientes na cultura do repolho. Conduziu-se o experimento a campo, na Horta de Pesquisas do Departamento de Fitotecnia da Universidade Federal de Viçosa, no período de 23/09 a 20/12/2002. Utilizouse o esquema parcelas subdivididas, delineamento inteiramente casualizado, com quatro repetições, sendo os espaçamentos dispostos nas parcelas e as doses de $\mathrm{N}$ nas subparcelas. Na colheita das cabeças, retiraram-se amostras das folhas as quais, após secas a $65^{\circ} \mathrm{C}$, foram submetidas às análises para os teores de $\mathrm{N}\left(\mathrm{N}_{-} \mathrm{NO}_{3}{ }^{-}\right.$e $\mathrm{N}$-total), $\mathrm{P}, \mathrm{K}, \mathrm{Ca}, \mathrm{Mg}$ e $\mathrm{S}$. Incremento das doses de $\mathrm{N}$ proporcionou aumento da produção de MS, dos teores de $\mathrm{N}$ ( $\mathrm{N}^{-\mathrm{NO}_{3}}$ - e $\mathrm{N}$-total), $\mathrm{P}$ e $\mathrm{Mg}$ e das quantidades de macronutrientes exportadas pela cultura. Aumento no espaçamento proporcionou maiores teores de $\mathrm{N}\left(\mathrm{N}_{-} \mathrm{NO}_{3}^{-}\right.$e N-total), $\mathrm{P}, \mathrm{S}$ e Ca, e menor produção de massa seca e da quantidade de K exportada pela colheita.
\end{abstract}

Termos para indexação: Brassica oleraceae var. capitata, qualidade, nitrato, população.

\section{ABSTRACT}

The effects of three plant spacings $(80 \times 30,60 \times 30$, and $40 \times 30 \mathrm{~cm})$ and five nitrogen rates $\left(0,75,150,225\right.$, and $\left.300 \mathrm{~kg} \mathrm{ha}^{-1}\right)$ were evaluated on biomass yield, macronutrient uptake and tissue concentration of cabbage. A field experiment was carried out at the Universidade Federal de Viçosa from 09/23 to 12/20/2002. The experiment was set in a split-plot design with four replications. Spacings were assigned to the main plots and the $\mathrm{N}$ rates were set in the split-plot, arranged in a completely randomized design. At the harvest time, leaves were detached, oven dried and analyzed for $\mathrm{N}\left(\mathrm{N}_{-} \mathrm{NO}_{3}^{-}\right.$and $\mathrm{N}$-total), $\mathrm{P}, \mathrm{K}, \mathrm{Ca}, \mathrm{Mg}$, and $\mathrm{S}$ contents. Increasing $\mathrm{N}$ rates led to an increase in biomass yield, $\mathrm{N}\left(\mathrm{N}_{-} \mathrm{NO}_{3}^{-}\right.$and $\mathrm{N}$-total), $\mathrm{P}$, and $\mathrm{Mg}$ contents and macronutrient uptake of cabbage. Increasing plant spacings led to lower biomass yield and $\mathrm{K}$ uptake and increase in $\mathrm{N}$ ( $\mathrm{N}_{-} \mathrm{NO}_{3}{ }^{-}$and $\mathrm{N}$-total), $\mathrm{P}, \mathrm{S}$, and Ca contents of cabbage.

Índex terms: Brassica oleraceae var. capitata, quality, nitrate, population.

(Recebido em 9 de novembro de 2006 e aprovado em 2 de setembro de 2008)

\section{INTRODUÇÃO}

Busca-se, na agricultura atual, maximização dos recursos produtivos visando aumentos em produtividade e qualidade dos alimentos produzidos, além da conservação do ambiente (AQUINO et al., 2005a). A diminuição do número de componentes familiares e a busca por produtos com maior qualidade tem gerado novas demandas à olericultura. No caso específico do repolho, há preferência por cabeças de tamanho médio de 1 a $1,5 \mathrm{~kg}$ e com menor teor de nitrato possível (AQUINO et al., 2005a,b; LÉDO et al., 2000).

O repolho é uma hortaliça folhosa e, como tal, o $\mathrm{N}$ tende a ser o nutriente de maior influência na produtividade e qualidade, pois além de estimular o crescimento foliar, é componente de aminoácidos e de proteínas (BORA et al., 1992). Na literatura, as doses de $\mathrm{N}$ recomendadas para a cultura do repolho, geralmente variam de 120 a $160 \mathrm{~kg} \mathrm{ha}^{-1}$. Entretanto, com o uso de cultivares mais responsivas e produtivas e da tendência crescente de se aumentar o

${ }^{1}$ Engenheiro Agrônomo, Mestre em Fitotecnia - Coordenadoria de Pesquisa e Pós-Graduação/CPPG - Instituto Federal do Norte de Minas Gerais Campus Januária/IFNM - Fazenda São Geraldo, sn - Bom Jardim - Cx. P. 97 - 39480-000 - Januária, MG - aquinoufv@yahoo.com.br 2Engenheiro Agrônomo, Doutor em Biologia Vegetal - Departamento de Fitotecnia/DFT - Universidade Federal de Viçosa/UFV - Avenida PH Rolfs, Departamento de Fitotecnia - Campus UFV - 36571-000 - Viçosa, MG - mpuiatti@ufv.br

'Engenheiro Agrônomo, Mestre em Fitotecnia - Instituto de Ciências Agrárias Universidade Federal de Uberlândia/UFU - Instituto de Ciência Agrárias Avenida Amazonas, s/n - Bloco 2E - Sala 25 - Campus Umuarama - 38400-902 - Uberlândia, MG - marcelomlelis@yahoo.com.br ${ }^{4}$ Engenheiro Agrônomo, Doutor em Solos e Nutrição de Plantas - Departamento de Fitotecnia/DFT - Universidade Federal de Viçosa/UFV - Avenida PH Rolfs, Departamento de Fitotecnia - Campus UFV - 36571-000 - Viçosa, MG - ppereira@ufv.br

${ }^{5}$ Engenheiro Agrônomo, Doutor em Fitotecnia - Centro de Ciências e Tecnologia Agroalimentar/CCTA/Campus de Pombal - Universidade Federal de Campina Grande/UFCG - Rua João Leite, 517 - Centro - 58840-000 - Pombal, PB - fhfpereira@ccta.ufcg.edu.br 
número de plantas/área visando menor massa de cabeça, essas doses podem ser insuficientes para se atingir o máximo potencial produtivo (AQUINO et al., 2005b).

Quando adequada, a fertilização nitrogenada favorece o crescimento vegetativo e, consequentemente, a expressão do potencial produtivo da cultura (AQUINO et al., 2005b; CARDOSO \& HIRAKI, 2001). Ainda, o ajuste de doses de $\mathrm{N}$ à cultura é importante para prevenir que o acúmulo de nitrato $\left(\mathrm{NO}_{3}^{-}\right)$nas plantas chegue a níveis não aceitáveis, os quais são observados quando essas são cultivadas em solos com excessiva disponibilidade do nutriente (MARSCHNER, 1995). Quando em altas concentrações no organismo humano, o nitrato pode formar nitrosaminas, que são carcinogênicas, além de causar a metahemoglobinemia, que leva à perda da capacidade da hemoglobina em transportar oxigênio (HIRONDEL \& HIRONDEL, 2001).

Nitrogênio e espaçamento influenciam na composição mineral das brássicas (KIMOTO, 1993; SILVA JÚNIOR, 1987). O acúmulo de $\mathrm{NO}_{3}^{-}$nas plantas, além do fator genético, também é influenciado por fatores ambientais, com destaque para intensidade de luz e temperatura, os quais interferem no metabolismo das plantas, sobretudo do N (MARSCHNER, 1995). Por outro lado, o espaçamento interfere diretamente na captação da energia radiante que, por sua vez, irá interferir na assimilação do $\mathrm{N}$ e no acúmulo de $\mathrm{NO}_{3}^{-}$.

Os espaçamentos comumente recomendados no cultivo de repolho variam de 70-80 cm entre linhas e 30-50 cm entre plantas (LÉDO et al., 2000; SADY et al., 2001). A redução no espaçamento proporciona menor massa de planta (cabeça) o que, por sua vez, pode ser benéfica, desde que a produtividade da cultura não seja reduzida, visto que melhora a qualidade estética das cabeças e sua aceitação comercial (AQUINO et al., 2005b). Entretanto, espaçamento e/ou dose de $\mathrm{N}$ influenciam diretamente no acúmulo de massa seca pela planta (BORA et al., 1992; SADY et al., 2001), alterando também o teor e a quantidade de minerais exportada pela colheita (SILVA JÚNIOR, 1987), os quais devem ser restituídos ao solo para manutenção da fertilidade (KIMOTO, 1993).

Objetivou-se, com este trabalho, avaliar os efeitos conjuntos de espaçamentos e de doses de $\mathrm{N}$ sobre a produção de biomassa seca, acúmulo de nitrato na massa fresca, teores e exportação de macronutrientes em repolho.

\section{MATERIALE MÉTODOS}

Conduziu-se o experimento a campo, na Horta de Pesquisas do Departamento de Fitotecnia da Universidade Federal de Viçosa (DFT/UFV), no período de 23/09 a 20/12/ 2002, utilizando-se o repolho híbrido Kenzan. As mudas, produzidas em bandejas de isopor de 128 células, em ambiente protegido, foram transplantadas com 4 ou 5 folhas completas, 28 dias após a semeadura.

O solo da área experimental, classificado como Argissolo Vermelho Amarelo, apresentou os seguintes atributos químicos: $\mathrm{pH}$ em $\mathrm{H}_{2} \mathrm{O}=6,1$ (relação 1:2,5); $\mathrm{P}=36$ $\mathrm{mg} \mathrm{dm}{ }^{-3}$ e K= $91 \mathrm{mg} \mathrm{dm}^{-3}$ (P-K: extrator Mehlich 1$) ; \mathrm{Ca}^{2+}=39$ $\mathrm{mmol}_{\mathrm{c}} \mathrm{dm}^{-3} ; \mathrm{Mg}^{2+}=8 \mathrm{mmol}_{\mathrm{c}} \mathrm{dm}^{-3} ; \mathrm{Al}=0,0 \mathrm{mmol}_{\mathrm{c}} \mathrm{dm}^{-3} ;(\mathrm{Ca}$, $\mathrm{Mg}$ e Al: extrator $\left.\mathrm{KCl} 1 \mathrm{~mol} \mathrm{~L}^{-1}\right) ; \mathrm{H}+\mathrm{Al}=23,1 \mathrm{mmol}_{\mathrm{c}} \mathrm{dm}^{-3}$

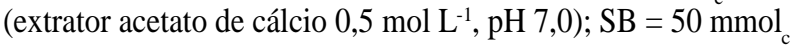
$\mathrm{dm}^{-3} ; \mathrm{V}=68 \% ; \mathrm{m}=0 \% ; \mathrm{e} \mathrm{M} . \mathrm{O}=19,2 \mathrm{~g} \mathrm{~kg}^{-1}$. Anteriormente à instalação do experimento, foram realizados sucessivos cultivos com milho, sem fertilização, objetivando-se reduzir os teores de $\mathrm{N}$ do solo.

Adotou-se o delineamento experimental inteiramente casualizado, no esquema de parcelas subdivididas, com quatro repetições. Nas parcelas, foram dispostos os três espaçamentos entre linhas $(80,60$ e $40 \mathrm{~cm})$ e nas subparcelas cinco doses de $\mathrm{N}\left(0,75,150,225\right.$ e $300 \mathrm{~kg} \mathrm{ha}^{-1}$ de $\left.\mathrm{N}\right)$. A subparcela foi constituída de quatro fileiras, com oito plantas cada, espaçadas de $30 \mathrm{~cm}$, totalizando 32 plantas, sendo consideradas úteis as duas fileiras centrais, excetuando-se $60 \mathrm{~cm}$ de cada extremidade.

O preparo do solo constou de uma aração, duas gradagens e abertura manual dos sulcos de plantio com auxílio de enxada. À exceção do N, as adubações foram realizadas com base na análise química do solo e recomendações para a cultura do repolho para o estado de Minas Gerais, conforme Ribeiro et al. (1999). No sulco de plantio foram aplicados: $300 \mathrm{~kg} \mathrm{ha}^{-1} \mathrm{de}_{2} \mathrm{O}_{5}, 36 \mathrm{~kg} \mathrm{ha}^{-1} \mathrm{de}$ $\mathrm{K}_{2} \mathrm{O}$ e $20 \%$ da dose total de $\mathrm{N}$ de cada tratamento, utilizando-se como fontes superfosfato simples, cloreto de potássio e uréia, respectivamente. Aplicou-se ainda, em plantio, o equivalente a $15 \mathrm{~kg} \mathrm{ha}^{-1}$ de sulfato de zinco, $10 \mathrm{~kg} \mathrm{ha}^{-1}$ de bórax, $10 \mathrm{~kg} \mathrm{ha}^{-1}$ de sulfato de cobre e $0,5 \mathrm{~kg}$ ha $^{-1}$ de molibdato de amônio (RIBEIRO et al., 1999).

Todos os fertilizantes aplicados no sulco de plantio foram distribuídos e incorporados ao solo cinco dias antes do transplante das mudas. Em cobertura, foram realizadas três adubações, com $\mathrm{N}$ e K, aos 20, 35 e 50 dias após o transplante (DAT) das mudas. Aos 20 DAT foram aplicados $20 \%$ da dose total de $\mathrm{N}$ e $36 \mathrm{~kg} \mathrm{ha}^{-1}$ de $\mathrm{K}_{2} \mathrm{O}$; e nas duas posteriores aplicou-se, em cada uma, $30 \%$ da dose total de $\mathrm{N}$ e $54 \mathrm{~kg} \mathrm{ha}^{-1}$ de $\mathrm{K}_{2} \mathrm{O}$.

Durante a condução do experimento realizaram-se duas capinas manuais para controle de plantas daninhas, aos 18 e 31 DAT. Realizou-se também, aos 28 DAT, uma pulverização à base de Deltametrina (Decis $25 \mathrm{CE}$ (), para o controle da traça das brássicas (Plutella xylostella). Quando necessárias, as irrigações foram realizadas por aspersão convencional.

Na colheita, que transcorreu dos 65 aos 83 DAT, foram coletadas as oito plantas centrais das duas fileiras 
centrais, em cada unidade experimental. As cabeças, depois de pesadas para obtenção da massa fresca, foram seccionadas longitudinalmente retirando-se uma fatia de $1,5 \mathrm{~cm}$ de espessura, a qual foi utilizada para determinação dos teores de massa seca e de macronutrientes. Após a secagem, em estufa com ventilação forçada de ar, a $65^{\circ} \mathrm{C}$ até peso constante, as amostras foram trituradas em moinho tipo Wiley equipado com peneira de 20 mesh. Dosou-se, posteriormente, o N-NO- ${ }_{3}^{-} \mathrm{N}-\mathrm{NH}_{4}^{+}$de acordo com Cataldo et al. (1975) e Jacson (1958), respectivamente, sendo Ntotal obtido pela soma das formas anteriores. O teor de $\mathrm{N}$ $\mathrm{NO}_{3}^{-}$foi expresso na massa fresca, considerando o teor de

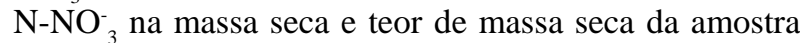
analisada. Após digestão nítrico-perclórica da matéria orgânica, dosou-se o P, colorimetricamente, pelo método de redução do fosfomolibdato pela vitamina C (BRAGA \& DEFELIPO, 1974); o K, por fotometria de emissão de chama; $\mathrm{Ca}$ e $\mathrm{Mg}$, por espectrofotometria de absorção atômica; e o S por turbidimetria do sulfato (BLANCAR et al., 1965). As quantidades exportadas de macronutriente na colheita foi obtida pelo produto da massa seca, teor de cada elemento e densidade populacional.

Os dados obtidos, das características avaliadas, foram submetidos às análises de variâncias utilizando-se do programa estatístico SAEG (RIBEIRO JÚNIOR, 2001), realizando-se análise de regressão para doses de $\mathrm{N}$ e teste de Duncan, a 5\% de probabilidade para os espaçamentos.

\section{RESULTADOS E DISCUSSÃO}

Houve interação espaçamentos x doses de $\mathrm{N}$ para produção de massa seca e teores de nitrato e de N-total na colheita (Tabelas 1 e 2); efeito de doses de $\mathrm{N}$ e de espaçamentos para teor de P na colheita (Tabelas 3 e 4); efeito de espaçamentos para teores de $\mathrm{S}$ e $\mathrm{Ca}$ e quantidade de K exportada na colheita (Tabela 4), e de doses de $\mathrm{N}$ para teor de $\mathrm{Mg}$ e quantidades exportadas pela colheita dos macronutrientes (Tabela 3). Não houve efeito dos fatores estudados para o teor de massa seca, sendo a média geral de $7,3 \%$.

A produção de massa seca de cabeça apresentou incrementos com o aumento das doses de $\mathrm{N}$, sendo o incremento maior nos menores espaçamentos (Tabelas $1 \mathrm{e}$ 2). Nos espaçamentos de 80 × $30 \mathrm{~cm}$ (E1) e de 40 × $30 \mathrm{~cm}$ (E3), a produção de massa seca aumentou linearmente até a dose máxima aplicada (300 $\left.\mathrm{kg} \mathrm{ha}^{-1} \mathrm{de} \mathrm{N}\right)$, alcançando valores de 6.271,57 e 9.033,57 $\mathrm{kg} \mathrm{ha}^{-1}$ de MS, respectivamente; no espaçamento de $60 \times 30 \mathrm{~cm}$ (E2) a maior produção estimada de massa seca de cabeça, 7.571,05 $\mathrm{kg} \mathrm{ha}^{-1}$, foi obtida com a dose de 250,34 $\mathrm{kg} \mathrm{ha}^{-1}$ de $\mathrm{N}$.

O $\mathrm{N}$ estimulou o crescimento das plantas, resultando em maior produção de massa seca. Aquino et al. (2005b) observaram incremento da área foliar das folhas externas à cabeça promovida pelo $\mathrm{N}$, o que resultou em maior captação de luz e, por conseguinte, maior produção de massa seca de cabeça. Por outro lado, a menor disponibilidade de $\mathrm{N}$ por planta, com o aumento do número de plantas por área (menor espaçamento), foi compensada pela maior população de plantas, resultando em maior produção de massa seca. Resultados dessa natureza também foram observados por Aquino et al. (2005b), e Bora et al. (1992) em repolho e por Ferreira et al. (2002) em couveda-Malásia.

Aumento das doses de $\mathrm{N}$, especialmente nos maiores espaçamentos, promoveu aumento do teor de nitrato na massa fresca (MF) das cabeças (Tabelas 1 e 2). De acordo com Marschner (1995), a disponibilidade de N é

Tabela 1 - Produção de massa seca e teores de nitrato e de N-total nas cabeças de repolho ‘Kenzan’ nos três espaçamentos em função de doses de $\mathrm{N}$ aplicadas.

\begin{tabular}{|c|c|c|}
\hline Espaçamento & Equações & $\mathrm{r}^{2} / \mathrm{R}^{2}$ \\
\hline & \multicolumn{2}{|c|}{ Produção de massa seca $\left(\mathrm{kg} \mathrm{ha}^{-1}\right)$} \\
\hline E1 $(80 \times 30 \mathrm{~cm})$ & $\mathrm{Y}=2209,57+13,54 \mathrm{X}$ & $0,76 * *$ \\
\hline $\mathrm{E} 2(60 \times 30 \mathrm{~cm})$ & $Y=2118,54+43,56 X-0,087 X^{2}$ & $0,88 * *$ \\
\hline $\mathrm{E} 3(40 \times 30 \mathrm{~cm})$ & $Y=2430,57+22,01 X$ & $0,84 * *$ \\
\hline & \multicolumn{2}{|c|}{ Nitrato nas folhas da cabeça na colheita $\left(\mathrm{mg} \mathrm{kg}^{-1}\right.$ de MF) } \\
\hline E1 $(80 \times 30 \mathrm{~cm})$ & $Y=54,30+0,39 X$ & $0,76 * *$ \\
\hline $\mathrm{E} 2(60 \times 30 \mathrm{~cm})$ & $Y=47,34+0,019 X+0,0015 X^{2}$ & $0,93 * *$ \\
\hline $\mathrm{E} 3(40 \times 30 \mathrm{~cm})$ & $Y=47,48-0,13 X+0,0011 X^{2}$ & $0,73 * *$ \\
\hline & \multicolumn{2}{|c|}{ N-total nas folhas da cabeça na colheita (dag kg ${ }^{-1}$ de MS) } \\
\hline E1 $(80 \times 30 \mathrm{~cm})$ & $\mathrm{Y}=2,59+0,0058 \mathrm{X}$ & $0,69 * *$ \\
\hline $\mathrm{E} 2(60 \times 30 \mathrm{~cm})$ & $Y=2,09+0,0043 X$ & $0,58 * *$ \\
\hline $\mathrm{E} 3(40 \times 30 \mathrm{~cm})$ & $Y=2,26+0,0042 X$ & $0,72 * *$ \\
\hline
\end{tabular}

\footnotetext{
*, ** Significativo a 1 e $5 \%$ de probabilidade, respectivamente, pelo teste $\mathrm{F}$.
} 
Tabela 2 - Produção de biomassa e teores de nitrato e de N-total nas cabeças de repolho 'Kenzan', em função de espaçamentos dentro de doses de $\mathrm{N}$ aplicadas.

\begin{tabular}{|c|c|c|c|c|c|}
\hline \multirow{2}{*}{ Espaçamentos } & \multicolumn{5}{|c|}{ Doses de $\mathrm{N}\left(\mathrm{kg} \mathrm{ha}^{-1}\right)$} \\
\hline & 0 & 75 & 150 & 225 & 300 \\
\hline & \multicolumn{5}{|c|}{ Produção de massa seca $\left(\mathrm{kg} \mathrm{ha}^{-1}\right)$} \\
\hline $\mathrm{E} 1(80 \times 30 \mathrm{~cm})$ & $1678,4 \mathrm{a}$ & $3645,8 \mathrm{a}$ & $4560,0 \mathrm{~b}$ & $5409,9 \mathrm{~b}$ & $5838,9 \mathrm{~b}$ \\
\hline E2 $(60 \times 30 \mathrm{~cm})$ & $2137,0 \mathrm{a}$ & $4846,5 \mathrm{a}$ & $6716,4 \mathrm{a}$ & $7500,3 \mathrm{a}$ & $7311,7 \mathrm{a}$ \\
\hline \multirow[t]{3}{*}{$\mathrm{E} 3(40 \times 30 \mathrm{~cm})$} & $2314,4 \mathrm{a}$ & $3687,4 \mathrm{a}$ & $6142,9 \mathrm{ab}$ & $8205,0 \mathrm{a}$ & $8308,1 \mathrm{a}$ \\
\hline & & $\mathrm{CV} 1=1 \mathrm{C}$ & & $15,42 \%$. & \\
\hline & \multicolumn{5}{|c|}{ Nitrato $\left(\mathrm{mg} \mathrm{kg}^{-1}\right.$ de $\left.\mathrm{MF}\right)$} \\
\hline $\mathrm{E} 1(80 \times 30 \mathrm{~cm})$ & $54,25 \mathrm{a}$ & $71,25 \mathrm{a}$ & $129,25 \mathrm{a}$ & $143,25 \mathrm{a}$ & $163,00 \mathrm{a}$ \\
\hline $\mathrm{E} 2(60 \times 30 \mathrm{~cm})$ & $44,00 \mathrm{a}$ & $34,50 \mathrm{a}$ & $67,00 \mathrm{~b}$ & $122,00 \mathrm{ab}$ & $174,50 \mathrm{a}$ \\
\hline \multirow[t]{3}{*}{$\mathrm{E} 3(40 \times 30 \mathrm{~cm})$} & $44,75 \mathrm{a}$ & $51,25 \mathrm{a}$ & $48,50 \mathrm{c}$ & $74,50 \mathrm{~b}$ & $110,50 \mathrm{~b}$ \\
\hline & & $\mathrm{CV} 1=2$ & & $19,05 \%$. & \\
\hline & \multicolumn{5}{|c|}{ N-total na colheita $\left(\right.$ dag $\mathrm{kg}^{-1}$ de MS) } \\
\hline E1 $(80 \times 30 \mathrm{~cm})$ & $2,74 \mathrm{a}$ & $2,73 \mathrm{a}$ & $3,39 \mathrm{a}$ & $4,44 \mathrm{a}$ & $4,06 \mathrm{a}$ \\
\hline $\mathrm{E} 2(60 \times 30 \mathrm{~cm})$ & $2,33 \mathrm{a}$ & $2,25 \mathrm{a}$ & $2,56 \mathrm{~b}$ & $2,99 \mathrm{~b}$ & $3,55 \mathrm{a}$ \\
\hline \multirow[t]{2}{*}{ E3 $(40 \times 30 \mathrm{~cm})$} & $2,30 \mathrm{a}$ & $2,44 \mathrm{a}$ & $3,09 \mathrm{a}$ & $3,08 \mathrm{~b}$ & $3,57 \mathrm{a}$ \\
\hline & & $\mathrm{CV} 1=12$ & & $11,46 \%$. & \\
\hline
\end{tabular}

Dentro de cada característica, médias nas colunas seguidas pela mesma letra, não diferem entre si pelo teste de Duncan, a 5\% de probabilidade.CV1=coeficiente de variação da parcela; $\mathrm{CV} 2=$ coeficiente de variação da subparcela.

um dos fatores mais importantes para o acúmulo de nitrato nas plantas. Maiores espaçamentos e/ou maiores doses de $\mathrm{N}$, resultaram em maior disponibilidade de $\mathrm{N}$ por planta e, consequentemente, em maiores teores de nitrato na MF. Ainda assim, o maior teor de nitrato observado no E2, de $174,50 \mathrm{mg} \mathrm{kg}^{-1}$ de MF, ou estimado de 188,04 $\mathrm{mg} \mathrm{kg}^{-1} \mathrm{de}$ MF, está abaixo dos encontrados por Sady et al. (2001) estudando formas de parcelamento de $\mathrm{N}$ sobre a produção e acúmulo de nitrato em repolho; também está bem abaixo dos limites estabelecidos na Comunidade Européia para hortaliças folhosas, que variam de 500 a $1500 \mathrm{mg} \mathrm{kg}^{-1} \mathrm{de}$ MF (SCHARPH, 1991, citado por AQUINO et al., 2005b) ou na Polônia, um dos mais exigentes da Europa, que varia de 250 a $2.000 \mathrm{mg} \mathrm{kg}^{-1}$ de MF (HIRONDEL \& HIRONDEL, 2001).

Nos três espaçamentos estudados houve resposta linear ao $\mathrm{N}$ aplicado quanto ao teor de $\mathrm{N}$-total na colheita (Tabela 1). O coeficiente linear da equação de regressão do E1 foi $26 \%$ e $28 \%$ maior que em E2 e E3, respectivamente. Tal fato deve-se, em parte, à maior disponibilidade de $\mathrm{N}$ por planta e, em parte, pela maior área foliar no maior espaçamento (AQUINO et al., 2005b), concorrendo para maior disponibilidade de luz e, por conseguinte, maior assimilação do N em formas orgânicas (MARSCHNER, 1995). Com relação aos espaçamentos dentro de doses, o teor de N-total diferiu apenas nas doses de 150 e $225 \mathrm{~kg} \mathrm{ha}^{-1}$ de N, o que pode ser explicado pela maior disponibilidade do nutriente por planta no maior espaçamento (E1) e efeito de concentração na MS.

$\mathrm{O}$ teor de $\mathrm{P}$ nas folhas da cabeça de repolho, apesar de significativo na análise de variância (teste F), não obteve bom ajuste $\left(\mathrm{R}^{2}\right)$ à equação polinomial. Dentro dos espaçamentos, o maior teor de P no E1 (Tabela 4) pode ser atribuído ao efeito de concentração devido ao menor acúmulo de MS nesse espaçamento (Tabelas 1 e 2); todavia, os valores médios dos espaçamentos foram inferiores aos encontrados por Furlani et al. (1978).

O teor de $\mathrm{Mg}$ nas folhas da cabeça de repolho apresentou aumento linear com incremento nas doses de $\mathrm{N}$ aplicadas, com 0,246 dag $\mathrm{kg}^{-1}$ de MS na maior dose aplicada. Esse valor é maior do que os encontrados por Warman \& Havard (1997) em cultivos orgânicos e convencionais de repolho. Para $\mathrm{S}$ houve efeito apenas de espaçamento, com maior teor nos espaçamentos E1 e E3, em relação ao E2 (Tabela 4). O Ca apresentou comportamento semelhante ao P (Tabela 4). Os teores de S e Ca encontrados nesse trabalho são maiores que aqueles encontrados em repolho por Furlani et al. (1978) e Warman \& Havard (1997), o que pode ser devido às diferenças entre os materiais genéticos utilizados e às características físico-químicas dos solos utilizados nos cultivos. 
Tabela 3 - Teores de P e de Mg na colheita e quantidade de macronutrientes exportada pela colheita do repolho, em função de doses de $\mathrm{N}(\mathrm{X})$ aplicadas.

\begin{tabular}{lll}
\hline \multicolumn{1}{c}{ Variáveis } & \multicolumn{1}{c}{ Equações } & $\mathrm{r}^{2} / \mathrm{R}^{2}$ \\
\hline $\mathrm{P}\left(\mathrm{dag} \mathrm{kg}^{-1} \mathrm{de} \mathrm{MS}\right)$ & $\mathrm{Y}=0,35-0,00035 \mathrm{X}+0,0000014 \mathrm{X}^{2}$ & $0,10^{*}$ \\
$\mathrm{Mg}\left(\mathrm{dag} \mathrm{kg}^{-1} \mathrm{de} \mathrm{MS}\right)$ & $\mathrm{Y}=0,21+0,00012 \mathrm{X}$ & $0,70^{*}$ \\
$\mathrm{~N}\left(\mathrm{~kg} \mathrm{ha}^{-1}\right)$ & $\mathrm{Y}=51,15+0,758 \mathrm{X}$ & $0,85^{* *}$ \\
$\mathrm{P}\left(\mathrm{kg} \mathrm{h}^{-1}\right)$ & $\mathrm{Y}=8,09+0,066 \mathrm{X}$ & $0,75^{* *}$ \\
$\mathrm{~K}\left(\mathrm{~kg} \mathrm{ha}^{-1}\right)$ & $\mathrm{Y}=84,68+1,48 \mathrm{X}-0,0026 \mathrm{X}^{2}$ & $0,68^{* *}$ \\
$\mathrm{Ca}\left(\mathrm{kg} \mathrm{ha}^{-1}\right)$ & $\mathrm{Y}=23,49+0,216 \mathrm{X}$ & $0,56^{* *}$ \\
$\mathrm{Mg}\left(\mathrm{kg} \mathrm{ha}^{-1}\right)$ & $\mathrm{Y}=5,18+0,0455 \mathrm{X}$ & $0,64^{* *}$ \\
$\mathrm{~S}\left(\mathrm{~kg} \mathrm{ha}^{-1}\right)$ & $\mathrm{Y}=13,15+0,259 \mathrm{X}-0,00046 \mathrm{X}^{2}$ & $0,70^{* *}$ \\
\hline
\end{tabular}

*,** Significativo a 1 e $5 \%$ de probabilidade, respectivamente, pelo teste $\mathrm{F}$.

Tabela 4 - Teores de fósforo (P), enxofre (S), cálcio (Ca) e quantidade de K exportada na colheita (KE), em função de espaçamentos na cultura do repolho.

Tabela 4 - Teores de fósforo (P), enxofre (S), cálcio (Ca) e quantidade de K exportada na colheita (KE), em função de espaçamentos na cultura do repolho.

\begin{tabular}{ccccc}
\hline Espaçamentos & $\mathrm{P}$ & $\mathrm{S}$ & $\mathrm{Ca}$ & $\mathrm{KE}$ \\
& & $\mathrm{dag} \mathrm{kg}^{-1} \mathrm{de} \mathrm{MS}$ & & $185,82 \mathrm{a}$ \\
$\mathrm{Eg}$ ( $(80 \times 30 \mathrm{~cm})$ & $0,39 \mathrm{a}$ & $0,76 \mathrm{a}$ & $1,19 \mathrm{a}$ & $231,75 \mathrm{a}$ \\
$\mathrm{E} 2(60 \times 30 \mathrm{~cm})$ & $0,31 \mathrm{~b}$ & $0,64 \mathrm{~b}$ & $0,93 \mathrm{~b}$ & $244,75 \mathrm{a}$ \\
$\mathrm{E} 3(40 \times 30 \mathrm{~cm})$ & $0,34 \mathrm{~b}$ & $0,72 \mathrm{a}$ & $1,04 \mathrm{~b}$ & 29,45 \\
\hline $\mathrm{CV}(\%)$ & 12,46 & 13,97 & 16,49 &
\end{tabular}

Dentro de cada característica, médias, nas colunas, seguidas por pelo menos uma mesma letra, não diferem entre si pelo teste de Duncan, a $5 \%$ de probabilidade.

Com relação às quantidades exportadas dos macronutrientes, houve resposta quadrática para $\mathrm{K}$ e $\mathrm{S}$ e linear para $\mathrm{N}, \mathrm{P}, \mathrm{Ca}$ e $\mathrm{Mg}$ ao $\mathrm{N}$ aplicado (Tabela 3). Considerando as doses de $\mathrm{N}$ para máxima produção de massa seca nos respectivos espaçamentos, as quantidades removidas de $\mathrm{N}, \mathrm{P}, \mathrm{K}, \mathrm{Ca}, \mathrm{Mg}$ e $\mathrm{S}$ pela colheita, foram: 278,$6 ; 27,9 ; 294,7 ; 88,3 ; 18,8$ e $49,5 \mathrm{~kg} \mathrm{ha}^{-1}$, respectivamente, em E1 e E3; e, a 240,9; 24,6; 292,2; 77,5; 16,6 e 49.2, respectivamente, em E2.

Quanto ao efeito de espaçamentos sobre a exportação de macronutrientes, esse foi significativo (teste F) apenas para o K exportado; todavia, apesar de, numericamente, aumentar com diminuição do espaçamento, não foi observada diferença estatística entre as médias pelo teste de média e nível de significância utilizados (Tabela 4).

\section{CONCLUSÕES}

Houve estímulo do N sobre a produção de massa seca de cabeça de repolho; o aumento foi linear nos espaçamentos $80 \times 30 \mathrm{~cm}$ (E1) e $40 \times 30 \mathrm{~cm}$ (E3), até a dose de $300 \mathrm{~kg} \mathrm{ha}^{-1}$ de $\mathrm{N}$, e quadrático no espaçamento $60 \times 30$ $\mathrm{cm}$ (E2), com produção máxima de massa seca na dose de $250,3 \mathrm{~kg} \mathrm{ha}^{-1} \mathrm{de} \mathrm{N}$.

Incremento das doses de $\mathrm{N}$ aumentaram os teores de $\mathrm{N}\left(\mathrm{N}^{-\mathrm{NO}_{3}}{ }^{-}\right.$e $\mathrm{N}$-total), $\mathrm{P}, \mathrm{Mg}$ e as quantidades de macronutrientes exportadas pela colheita.

$\mathrm{O}$ maior teor de nitrato nas folhas encontrado (174,50 mg N-NO ${ }_{3}^{-} \mathrm{kg}^{-1}$ de massa fresca) ou estimado (188,04 mg N-NO ${ }_{3}^{-} \mathrm{kg}^{-1}$ de massa fresca) no E2, ficou abaixo do limite tolerável em países da Europa.

$\mathrm{O}$ aumento no espaçamento proporcionou maiores teores de $\mathrm{N}\left(\mathrm{N}_{-} \mathrm{NO}_{3}{ }^{-}\right.$e N-total), $\mathrm{P}, \mathrm{S}$ e Ca e menor produção de massa seca e quantidade de $\mathrm{K}$ exportada pela colheita.

\section{AGRADECIMENTOS}

Ao CNPq, pela bolsa de Doutorado concedida ao primeiro autor. Ao CNPq e a FAPEMIG, pelos recursos financeiros. 


\section{REFERÊNCIAS BIBLIOGRÁFICAS}

AQUINO, L. A.; PUIATTI, M.; PEREIRA, P. R. G.; PEREIRA, F. H. F.; CASTRO, M. R. S.; LADEIRA, I. R. Características produtivas do repolho em função de espaçamentos e doses de nitrogênio. Horticultura Brasileira, Brasília, v. 23, n. 2, p. 266-270, 2005a.

AQUINO, L. A.; PUIATTI, M.; PEREIRA, P. R. G.; PEREIRA, F. H. F.; LADEIRA, I. R.; CASTRO, M. R. S. Efeito de espaçamentos e doses de nitrogênio sobre as características qualitativas da produção do repolho. Horticultura Brasileira, Brasília, v. 23, n. 1, p. 100-104, 2005b.

BLANCHAR, R. W.; REHM, G.; CALDWELL, A. C. Sulfur in plant material by digestion with nitric and perclórico acid. Proceedings Soil Science Society of America, Monticello, v. 29, n. 1, p. 71-72, 1965.

BORA, G. C.; DEKA, B. C.; SHADEQUE, A. Effect of different levels of nitrogen and spacing on head yield of cabbage (Brassica oleraceae convar capitata var capitata). Indian Journal of Agricultural Sciences, New Dehli, v. 62, n. 8, p. 527-528, 1992.

BRAGA, J. M.; DEFELIPO, B. Determinação espectrofotométrica de fósforo em extratos de solos e plantas. Revista Ceres, Viçosa, v. 21, n. 113, p. 73-85, 1974.

CARDOSO, A. I. I.; HIRAKI, H. Avaliação de doses e épocas de aplicação de nitrato de cálcio em cobertura na cultura do rabanete. Horticultura Brasileira, Brasília, v. 19, n. 3, p. 328-331, 2001

CATALDO, D. A.; HAROON, M.; SCHRADER, L. E.; YOUNGS, V. L. Rapid clorimetric determination of nitrate in plant tissue by nitrification of salicylic acid. Communication in Soil Science and Plant Analysis, Monticello, v. 6, n. 1, p. 71-80, 1975.

FERREIRA, W. R.; RANAL, M. A.; FILGUEIRA, F. A. R. Fertilizantes e espaçamento entre plantas na produtividade da couve-da-Malásia. Horticultura Brasileira, Brasília, v. 20, n. 4, p. 635-640, 2002.

FURLANI, A. M. C.; FURLANI, P. R.; BATAGLIA, O. C.; HIROCE, R.; GALLO, J. R. Composição mineral de diversas hortaliças. Bragantia, Campinas, v. 37, n. 5, p. 33-44, 1978.

HIRONDEL, J. I.; HIRONDEL, J. L. I. Nitrate and man: toxic, harmless or beneficial? New York: CAB, 2001. $168 \mathrm{p}$.

JACSON, M. L. Nitrogen determination for soil and plant tissue. In: . Soil chemical analysis. Engiewood Chiffs: Prentice Hall, 1958. p. 183-204.

KIMOTO, T. Nutrição e adubação de repolho, couve-flor e brócolo. In: FERREIRA, M. E.; CASTELLANE, P. D.; CRUZ, M. C. P. (Eds.). Nutrição e adubação de hortaliças. Piracicaba: Associação Brasileira para Pesquisa da Potassa e do Fosfato, 1993. p. 149-178.

LÉDO, F. J. S.; SOUZA, J. A.; SILVA, M. R. Avaliação de cultivares e híbridos de repolho no Estado do Acre. Horticultura Brasileira, Brasília, v. 18, n. 2, p. 138-140, 2000 .

MARSCHNER, H. Mineral nutrition of higher plant. 2. ed. New York: Academic, 1995. 889 p.

RIBEIRO, A. C.; GUIMARÃES, P. T. G.; ALVAREZ, V. H. Recomendações para o uso de corretivos e fertilizantes em Minas Gerais: $5^{a}$ aproximação. Viçosa, MG: Comissão de Fertilidade do Solo do Estado de Minas Gerais, 1999. 359 p.

RIBEIRO JÚNIOR, I. R. Análises estatísticas no SAEG. Viçosa, MG: UFV, 2001. 301 p.

SADY, W.; WOJCIECHOWSKA, R.; ROZEK, S. The effect of form and placement of $\mathrm{N}$ on yield and nitrate content of white cabbage. Acta Horticulture, The Hague, n. 563, p. 123-128, 2001.

SILVA JÚNIOR, A. A. Adubação mineral e orgânica em repolho: II. concentração de nutriente na folha e precocidade. Horticultura Brasileira, Brasília, v. 5, n. 1, p. 15-17, 1987.

WARMAN, P. R.; HAVARD, K. A. Yield, vitamin and mineral contents of organically and conventionally grown carrots and cabbage. Agriculture, Ecosystems and Enviromment, Amsterdam, v. 61, p. 155-162, 1997. 